\title{
Translation as memory
}

\author{
Gang Wang \\ School of Foreign Languages, Sun Yat-sen University, Guangzhou 510275, China. \\ wgjack912@126.com
}

Keywords: translation, memory, Lin Shu.

\begin{abstract}
It is believed that metaphor can lead to the emergence of a new intricate understanding of a phenomenon which otherwise would be hard or even impossible to formulate. This might explain why we have many metaphors for the perplex concept of translation. This paper attempts to offer an alternative perspective in which the mechanism of translation is compared with that of memory. By exploring how and why memory brings us to the past, we might be able to better understand what actually happens in translation.
\end{abstract}

\section{Introduction}

Translation has been approached as many different metaphors. Among them were translation as conversation [1], translation as rewriting and manipulation [2], translation as cultural construction [3], translation as communication [4], translation as negotiation [5], to name a few. Those metaphors are like lens though which the complexities of translation are revealed. They also serve as different ways of "reading" that culminate in fresh understandings of translation. Due to the growing recognition of the role of metaphor for human cognition [6], it is almost tempting to think of the lights that the metaphor "translation as memory" may shed on our understanding of translation.

\section{The possibility of Projecting Memory on Translation}

It is not hard to see that memory and translation share much in common. From a traditional perspective, memory is a path between the past and the present while translation is a medium between the foreign and the native. In memory, we get in touch with the past; through translation, we have a glimpse of the foreign. But at the same time, it seems that both memory and translation can not be completely trusted. How can we be sure what we remember is a real picture of the unfathomable past, and how can we be certain that what is translated does render the spirit of the original?

It is becoming increasingly impossible to offer any answer to these question as the old conceptions of the foreign and the past collapsed in today's world permeated with "the inconsistencies, the aporias, and the undecidabilities” [7]. Plumb declares Death of the Past. Bathes proclaims Death of the Author. In this almost haunted post-modern climax, it is too naive to think of anything as stable and certain. The past or the original has become something like a spectre-----fickle, complicated, and sometimes almost inexplicable. If there is no certain, existent past or original available for comparison, the conventional concept of memory being the account of the past and translation being reduplication for the original becomes dubious.

It is quite self-evident that besides the past, memory also links with the present; similarly besides the source, translation has a tie with the target. If we only judge the virtue of memory by its 
resemblance to the past, and translation by its equivalence to the original, then we fail to give enough attention to the relation between memory and the present, or translation and its target.

\section{Memory: its Relation with the Past and the Present}

The study on memory experienced a shift from "the past" to "the present". By recognizing that the past is something ever-becoming, never complete, and perhaps forever unknown, more and more researchers are now trying to explain memory in the present tense. The key question seems to have changed from "what" to "how and why". This shift in memory studies is interesting, and may offer us alternative ways to view translation as well.

Let's ponder a bit on the tetchy subject of memory. I call memory tetchy because it is doomed to be an endless race against time, a desperate chase after the past. The anxiety of memory comes from the fact that it attempts to represent the past, a concept which is murky in itself. Wrapped in the fog of time, the past is nothing that can be pierced with certainty. Since there is no such thing as a time machine that can take us to the past, there is no way we can be sure what a real past means. As Borges speculates that we may only have "a fictitious past occupies in our memories", or "a past of which we know nothing with certainty---not even that it is false" [8]. To admit that there is no way for us to know the past, does not mean that we should not believe its existence, and definitely does not mean that it can not be described.

In fact, to name or to think of things past implies their existence. We may get skeptic towards any single account of the past, but we can not disavow every account of it; we may falsify some of our memories, but we can not imperil the entire implications for human credibility. At the very least, we remember what we did just now, recall that there was a yesterday, and sense the process of growth and decay. And we do have all the physical and archeological evidence that marks the apparent pre-existence. Although we might never gather enough evidence to know all the unproven events in the unproven years, we have to take faith in the past. Harold Pinter expressed this idea very explicitly: "The past is what you remember, imagine you remember, convince yourself you remember, or pretend to remember" [9]. Pretence is meaningless if nobody believes. We pretend because we hope to believe, want others to believe, and in the end sometimes actually believe. In other words, although we can never truly know it, we have to believe there had been a past, because it keeps haunting us through our present memory.

The past survives in our memory. "Survives", not "exists". This implies that we should cease to regard the past as a simple objective certain truth that waits to be revealed, but as something alive. To remember is to make the past active in the present. It is the lively memory that brings the elusive past to our reach and endowed it with life. In memory, the past is all around us, shaping the way we view the world, and insinuating its lessons for the present. The purpose of memory, therefore, is not merely to preserve or even to present the past, but more importantly to keep it alive, to adapt it so as to enrich the present.

Now it seems easier for us to define the relationship of memory and the past, as well as that of memory and the present. Things happened in the past makes the memory possible. If there is no past, there is no memory in the first place. It is in this sense that we have to believe in the past so as to start remembering. But far from simply holding on previous experiences, memory understands and reconstructs them according to the present needs. In other words, the past is the cause of memory, while the present is its reason. In Tennyson's "Ode to memory", he expressed this idea explicitly: "Memory, which steals "fire / From the fountains of the past, /To glorify the present." Interestingly in China we have a very similar metaphor of "stealing fire” for translation. Lu Xun, the father of modern Chinese literature, regarded the translator as Prometheus and commented that 
their task is to steal fire from the foreign so as to illuminate the native.

\section{Translation: its Relations with the Source and the Target}

The past has been the focus in the traditional study of memory; in a similar way, translation theory used to put much emphasis on the source text. If now we agree on the importance of the present to memory, we should also take a second thought on the current asymmetric relationships among translation, its source and target.

In translation proper, there used an implicit law, that is, the target text produced by the translator must aims at establishing some kind of equivalence to the original. "Equivalence" certainly is one of the most controversial terms in Translation Studies, which has been constructed, deconstructed and reconstructed in many different ways, Textual equivalence of Catford [10], formal vs. dynamic equivalence of Nida [11], semantic vs. communicative equivalence of Newmark [12], semantic vs. functional equivalence of Bell [13], etc. But all these different "equivalences" are based more or less on the same underlying assumption: the sacred status of the original. In reality translation is never a mere task of sending information from the source; it is also about how this information is received in the target. What we have reflected about memory, in particular, the relations of memory with the past and the present, might help to explain what happens among translation, the source and the target.

The task of translation to quest for the source, is somehow like the endless and desperate task of memory trying to catch up with the past. There is no tangible past, and there is no definite original. Once the text is produced, it is "a machine for eliciting interpretations" [14]. Even the author is no longer in the position to offer any kind of authoritative reading guidelines. The fact that the text is open does not imply that the text is not meaningful in itself. But rather, it reminds us the fact that it is impossible for any reader, even the translator, to declare his interpretation represents the real intention of the text. With many influencing or manipulative variables ranging from subtle textual nuances to the overall socio-cultural framework, any version of interpretation is at best to be credited as a probable.

Although we have no way to be sure what the original really is, we have to respect the fact that the source text occurs prior to translation, and therefore gained its status of sacred originality. Without the original text, there is no such thing as translation. Even in pseudo-translation, the writer/translator always has to claim that they work with a fictional original. The source text, we can say, is the cause of translation, in the same way that the past is the cause of memory.

What about the other side of translation-----how can we define the relation between translation and the target? Translation first of all has to appear in the form of a target language, and then most probably to be received in a target culture. The target context might voluntarily initiate the translation because it feels curious towards the foreign. Or a translation might be imposed on the target culture, based on the assumption that the target is in need for this particular idea being translated. What triggers translation in either case lies with the concerns of the target. In Toury's words, "translation is basically designed to fulfill what is assumed to be the needs of the culture which would eventually host it” [15]. In other words, the target is the reason for translation.

Situated between the cause of the original and the reason of the target, translation has double responsibilities to fulfill. It has to quest for the meaning of the original text and at the same time understand the needs of the target context. I felt that the second task was somehow neglected in the traditional "source-oriented" translation criticism. It is necessary to look at translation from different perspectives. Away from the source-oriented position, we can ask questions like why and how the target context needs a particular text to be translated. I believe such inquiries are necessary 
for translation to restore a balance between the source and the target, or in other words, to achieve a harmony between its cause and its reason.

\section{The case of Lin Shu}

My inquiry starts with Li Shu's translation. Lin is the most prolific and influential translators in China in late $19^{\text {th }}$ and early $20^{\text {th }}$ Century. He translated more than 180 works of foreign literature into classical Chinese. Despite of the general acknowledgement of his impact on the emergence and development of modern Chinese literature, Lin Shu and his translations remains a controversial topic.

There have been several reasons for the negative assessment of Lin's translation. One of the most prevailing criticisms is towards his free translation style. Li Shu did his translation without any knowledge of foreign language. He collaborated with his friends who orally relayed the original for him. He himself admitted this problem in the postscript to one of his translations: "As I did not understand western languages, I could only take down what I heard, so I was completely ignorant even if some errors occurred" [16].

However, the problem is more than a language issue. Lin Shu is also criticized for inclining to acting as a commentator and giving voice to his own views when he is telling the story. For example, in Gulliver's Travel, Gulliver explained the two Houses in the English parliament for the king of Brobdingnag like this: "and these two bodies make up the most august Assembly in Europe, to whom, in conjunction with the prince, the whole legislature is committed". In Lin Shu's translation, he added one sentence of his own explanation, which means in English "the upper level and the lower level can then be linked up and this is the source of constitution". He added this explanation according to his own political stand as an advocator of constitutional monarchy. Such examples can be easily found in his translations.

If judged by the source-oriented protocol, Lin Shu can barely be regarded as a translator, but rather at best a second-hand storyteller. But if we want to get a better picture of Lin Shu's translation, we will have to take the target culture and society into consideration, and try to find out why and how Lin Shu translated in that specific context. The target context of Lin Shu's translation is perhaps one of the most chaotic times in Chinese history. He lived through the Opium War (1839-1942), the Tai Ping Rebellion (1851-1864), the Sino-Japanese War (1894-1895), the Constitutional Revolution in 1898, the allied foreign forces invasion, the Republican Revolution of 1911, the establishment of Republic of China in 1912, and the following warring chaos among the warlords, the new cultural movement from 1919...It is impossible to expand the whole picture here and analysis in detail what China was really in need of at that time. There is one thing very certain: The foreign invasion and dynastic collapse in the beginning of $20^{\text {th }}$ century throw the whole nation into turmoil. National salvation was the top priority for most intellectuals at that time. To learn from more advanced countries and to carry out social reform in China is the preoccupation.

Lin Shu and his contemporary Yan Fu should be regarded as pioneers who introduced new ideas into China. While Yan Fu rendered many western works of social sciences into China, Lin was devoted to literary translation. Lin Shu's translation was very popular and many of the novels he translated were bestsellers at that time. Several prominent modern writers, like Lu Xun, Ba Jing, Bin Xin and Qian Zhongshu, admitted that they devoured Lin Shu's translation and it had been the inspiration for their own literary creation. The works Lin translated helped to change the prejudice of the Chinese against western literature and established a new literary genre of novel in China. More importantly, literary works has the magic power of arousing sentiments and allowing new ideas to seep in. Some of Lin Shu's translation, like Joan Haste and La Dame aux Camélias, are 
daring challenges to the old Chinese moral standards; and others, like Uncle Tom's Cabin and David Copperfield, expressed the expectation for democratic politics and social equality. Taking this into consideration, even the above mentioned extra "commentary" in Lin Shu's translation practice can be understood in a positive way. He hopes his literature can help the nation to be more aware of its own fate. Although in Lin Shu's translation, most new ideas are only in the making, they played an active role and influenced the New Cultural Movement later.

There is one thing that has to be mentioned within the "target-oriented" re-evaluation of Lin Shu's translation. Lin Shu translated only into classical Chinese. His negative attitude towards vernacular language (Bai Hua) and his conservative views towards the New Cultural Movement brought Lin Shu lots of severe criticisms. After Lin Shu published two articles "Should Classical Chinese be Abolished" and "On the Growth and Decay of Classical and Vernacular Chinese" in defense of classical Chinese, the advocates of New Cultural Movement launched a cultural debate against Lin Shu, in which he was rebuked as an obstinate defender of the feudal culture and a difficult enemy of social progress. Followed by the collapse of Lin's reputation, his translations are also mocked, negated and depreciated.

This highly politicized analysis of Lin Shu and his translation seems to me quite unfair. It is true that today it seems that the vernacular language and New Cultural Movement are both revolutionary and progressive. However, it is not justified to label Lin Shu as reactionary only because he did not agree with the radical idea of the total repudiation of the traditional Chinese culture. His insistence in using classical Chinese for his translation is easily justified. Waley, a well-known English translator of Chinese literature, had a good command of classical Chinese. After his reading of Lin Shu's work, he defended the translator by saying:

"The translator must use tools he knows best how to handle. And this reflection reminds me at once of what Lin Shu, the great early $19^{\text {th }}$ century translator of European fictions into Chinese, said when he was asked why he translated Dickens into ancient Chinese instead into modern colloquial, his reply was ‘because ancient Chinese is what I am good at.” [17]

Away from the source-oriented view, we can see that Lin Shu's translation introduced revolutionary ideas and new literature genres into China. These had great impact on the transition of Chinese literature and society. Although strictly speaking his translations are not "faithful” to the source text, he managed to help the Chinese reader to get a glimpse of the original. Hu Shi, despite his disagreements with Lin Shu during the debate in New Cultural Movement, gave very truthful comment on Lin's translation:

"In all fairness, Lin Shu made achievements in his experiment in applying classical Chinese to the translation of foreign novels. Classical Chinese has never been used for writing a novel, but Lin Shu translated over 100 novels into classical Chinese, and now there are more people starting to do translate foreign novels; classical Chinese does not accommodate styles of humor, but Lin translated Dickens and Irving; classical Chinese is shy at describing love, but now we have Joan Haste and La Dame aux Camélias. What a surprise!” [18]

Translation is never a mere task of sending information from the source; it is also about how this information is received in the target. If the ultimate reason of translation is to serve the target language and culture, the assessment of translation should also highlight the target context in question. While Lin Shu was translating the foreign literature, he was doing so in his mind with the Chinese reader and China at that specific point in history. And as we are re-evaluating Lin Shu and his achievements in translation in modern Chinese history, we are also getting to know better how and why we are going to translate today. 


\section{Summary}

By drawing an analogy between memory and translation, and with the case of re-evaluating Lin Shu, I would like to close here with a call for a revising of the conventional concept of translation being reduplication for the original. It should be recognized that just like memory that is never simply a representation of the past, the role of translation is no longer a passive servant for the source text. Instead, each translation becomes a story, a document, a record or a memory of the original, which continues and extends its life into a foreign soil. That is why we see translation as memory, that is made necessary and possible by the change of time, that confirms and affirms something alien, that constructs the identity by recording a continuum of a legacy, and that most important of all, always starts from now and here.

\section{References}

[1] D.Robinson, The Translator's Turn, John Hopkins University Press, Baltimore, 1991.

[2] A. Lefevere, Translation, Rewriting, and the Manipulation of Literary Fame, Routledge, London, 1992.

[3] S. Bassnett, A. Lefevere (Ed.), Constructing Cultures: essays on literary translation, Multilingual Matters, Clevedon, 1998.

[4] E. Gutt, Translation and Relevance : Cognition and Content, St. Jerome, Manchester, 2000.

[5] U. Eco, Mouse Or Rat? : Translation as Negotiation, Weidenfeld and Nicolson, London, 2003.

[6] G. Lakoff, M. Johnson, Metaphors We Live By, Unversity of Chicago Press, Chicago, 2003.

[7] K. Koskinen, T. Yliopisto, Beyond Ambivalence : Postmodernity and Ethics of Translation, University of Tampere,Tampere, 2000.

[8] J. L. Borges, Labyrinths: Selected Stories and Other Writings, Penguin, Harmondsworth, 1970.

[9] http://www.azquotes.com/quote/781787

[10] J. Catfor, A Linguistic Theory of Translation, Oxford University Press, Oxford, 1965.

[11] U. A. Nida, C. R. Taber, The Theory and Practice of Translation, E. J. Brill, leiden, 1969.

[12] P. Newmark, Approaches to Translation, Pergamon, Oxford, 1981.

[13] R. T. Bell, Translation and Translating: Theory and Practice, Longman, London, 1991.

[14] U. Eco, Experience in Translation, University of Toronto Press, Toronto, 2001.

[15] G. Toury, Descriptive Translation Studies and Beyond, Benjamins, Amsterdam, 1995.

[16 ]X. Zhu, The Works from Chunjue Study (Chunjue Zhai Zhusu Ji), Shijie Shuju, Shanghai, 1949.

[17] A. Waley, Arthur Waley on Lin Shu, Rendition 5 (1997).

[18] S. Hu, The Selected Eassys of Hu Shi, Yuandong Press, Shanghai, 1930. 